\title{
Influence of temperature and fat content on ideal sucrose concentration, sweetening power, and sweetness equivalence of different sweeteners in chocolate milk beverage
}

\author{
J. A. Paixão, ${ }^{* 1}$ J. B. Rodrigues, ${ }^{*}$ E. A. Esmerino, ${ }^{*}$ A. G. Cruz, $†$ and H. M. A. Bolini* \\ *Departamento de Alimentos e Nutrição. Faculdade de Engenharia de Alimentos (FEA) Universidade Estadual de Campinas (UNICAMP), \\ Campinas, 13083-862, São Paulo, Brazil \\ †Instituto Federal de Educação, Ciência e Tecnologia do Rio de Janeiro (IFRJ), Maracanã, 20270-021, Rio de Janeiro, Brazil
}

\begin{abstract}
The introduction of new products catering to specific dietary needs and the corresponding changes in the consumer profile reflect a growing demand for diet and "light" products. However, little information is available regarding the sensory effects of different sweeteners in products consumed at different temperatures and with varying fat contents. In this regard, this study aimed to determine the influence of temperature and fat content on the ideal sucrose concentration and the sweetness equivalence and sweetening power of different sweeteners: Neotame (NutraSweet Corp., Chicago, IL), aspartame, neosucralose, sucralose, and stevia ( $95 \%$ rebaudioside A), with sucrose as reference, in a chocolate milk beverage using a just-about-right (JAR) scale and magnitude estimation. Increasing temperature of consumption had an inverse effect on the ideal sucrose concentration in whole milk beverages, whereas no difference was noted in beverages made skim milk. In addition, a decrease in sweetening power was observed for all of the sweeteners analyzed considering the same conditions. The findings suggest that different optimal conditions exist for consumption of chocolate milk beverage related to sweetness perception, which depends on the fat level of milk used in the formulation. This information can be used by researchers and dairy processors when developing chocolate milk beverage formulations.
\end{abstract}

Key words: chocolate milk beverage, temperature, fat content, sweetener

\section{INTRODUCTION}

The rates of obesity and other diseases related to excessive consumption of sucrose increase every day, along with consumer concerns about body image. Ac-

Received January 29, 2014.

Accepted August 23, 2014.

${ }^{1}$ Corresponding author: jualvesbiomed@gmail.com cordingly, consumer demand has increased for sensorially appealing products with low caloric content and high nutritional value. According to the Brazilian Dietetic and Special Purpose Foods Association (ABIAD, 2011), the market for "light" and diet products has grown approximately $800 \%$ in the last decade. To meet the demand of this growth market, companies have developed alternatives such as substitution of sucrose with sweeteners (Nabors and Lemieux, 1993).

Sweeteners are natural or artificial substances with high sweetening power but low caloric content compared with sucrose. Sweetening power varies according to the product and its characteristics (Nabors, 2002). In a study investigating a soluble powder tea drink, differences in sweetening power were detected with increasing temperature of consumption (Cardoso et al., 2004). However, this effect does not apply to all products because many factors other than temperature influence the perception of flavors and tastes. One such factor is fat, which plays an important role in the formulation of many foods and is considered a key ingredient for the sensory and physiological characteristics of food products (Pinheiro and Penna, 2004).

The successful substitution of sucrose by sweeteners requires sensory studies, such as the evaluation of the ideal sucrose concentration and sweetness equivalence relative to that of sucrose. An acceptance test using the just-about-right (JAR) scale is one of the most frequently used methods for determining the optimal amount of an ingredient to be added with respect to the sensory needs of the consumer. Its wide use reflects its reliability, the validity of its results, and the ease of use by researchers (Meilgaard et al., 2006). Another widely used approach is the magnitude estimation method, which provides a graphical representation of the results standardized by Stevens' law (Stone and Oliver, 1969). Magnitude estimation is one of the most commonly used methods to obtain sweetness equivalency as related to sucrose and it has been successfully used in many processed products (Palazzo et al., 2011; Cadena and Bolini, 2012; Freitas et al., 2014). 
Chocolate milk beverage is a popular and regularly consumed food, with wide sensory acceptance among consumers of different age groups and socio-economic levels. The product is consumed at different temperatures, and its sweet taste is an attribute that contributes to product acceptance by consumers (Shepard et al., 2013). A recent report suggests that $87 \%$ of consumers regularly purchase chocolate milk (Brazilian Association of Private Brands and Outsourcing; ABMAPRO, 2011). Several formulations of chocolate powder are presently available commercially, and all have a basic composition of approximately 30\% sucrose or other sugars (Varnam and Sutherland, 1997). Because this fraction corresponds to a significant component of total caloric content, it presents an opportunity for the development of products with reduced levels of sugar and calories.

In this context, the aim of present study was to evaluate the effect of fat content and different consumption temperatures on ideal sucrose concentration and equivalent concentration of different sweeteners: aspartame, Neotame (NutraSweet Corp., Chicago, IL), neosucralose blend, sucralose, and stevia in chocolate milk.

\section{MATERIALS AND METHODS}

\section{Materials}

Powdered Camponesa whole milk (lot \# 221009) and skim milk (lot \# 010904; Lagoa da Prata, Minas Gerais, Brazil) were prepared and used as directed on product label. Chocolate powder (lot \# 23581216; Nestlé, Araras, São Paulo, Brazil) was added at levels determined through an ideal chocolate concentration test conducted in advance with consumers of the product.

The beverage prepared with chocolate powder was sweetened with 5 different sweeteners permitted by Brazilian legislation (Brazil National Health Surveillance Agency, 2008): aspartame (Sweetmix, Sorocaba, São Paulo, Brazil), stevia leaf extract (95\% rebaudioside A, Cargill, São José do Rio Pardo, São Paulo, Brazil), sucralose (Sweetmix, Sorocaba, São Paulo, Brazil), neosucralose (blend of Neotame, acessulfame-K, and sucralose; Sweetmix), and Neotame (NutraSweet Corp.).

\section{Sample Preparation}

The chocolate milk beverage samples were prepared 2 $\mathrm{h}$ before the tests by adding $110 \mathrm{~g}$ of chocolate powder, as determined by using a JAR scale (Desai et al., 2013; amount determined according to section 2.2.1), to $1.0 \mathrm{~L}$ of mineral water. Five different sucrose concentrations
$(5,7.5,10,12.5$, and 15\%) were used for analysis of ideal sweetness.

For the magnitude estimation method, samples were prepared with 5 different sweeteners; Table 1 shows predefined concentrations used for analysis at $6 \pm 2^{\circ} \mathrm{C}$ in whole and skim milk and $45 \pm 2^{\circ} \mathrm{C}$ for whole milk. Samples were heated in a water bath until reaching the desired temperature and then placed in thermally insulated containers with controlled temperature to maintain a constant temperature. For samples to be consumed at $6 \pm 2^{\circ} \mathrm{C}$, samples were prepared and immediately chilled. Samples were monitored with a thermometer to ensure a constant temperature.

\section{Sensory Analysis}

For the ideal tests, the samples were presented monadically, using a balanced complete block design (MacFie et al., 1989). The tasters evaluated the samples using a JAR scale with 9-cm nonstructured scale anchored at the extremities with "much less sweet than the ideal" and "much sweeter than the ideal," with the central point being the ideal concentration to add to the product (Esmerino et al., 2013). The tasters were instructed to indicate the perceived chocolate flavor stimulus and sweetness stimulus on the scale.

All tests were conducted at Laboratory of Sensory Science and Consumer Research of the Department of Food and Nutrition (DEPAN) at the State University of Campinas (UNICAMP, Brazil). The booths were equipped with FIZZ Network Sensory Software (Biosystemes, Couternon, France). Different assessors were used in the each test.

\section{Ideal Chocolate Powder Concentration}

Five formulations of prepared chocolate milk beverage were used. The chocolate powder concentrations analyzed were $10,15,20,25$, and $30 \mathrm{~g} / 160 \mathrm{~mL}$ of product, which were established using the recommended amount of chocolate powder on commercial brand labels $(20 \mathrm{~g} / 160 \mathrm{~mL})$ as the central point. For this test, we used 100 consumers of chocolate milk beverage, in accordance with Morais et al. (2014). The consumers were aged from 18 to $54 \mathrm{yr}$, and the majority were women (84\%).

\section{Ideal Sucrose Concentration}

To determine the ideal sucrose concentration, 5 formulations of chocolate milk beverage were prepared. The sucrose concentrations analyzed were $5,10,15,20$, and $25 \%$ (wt/wt), for skim and whole milk at $6{ }^{\circ} \mathrm{C}$ and $45^{\circ} \mathrm{C}$, which were established using the amount of sugar 
Table 1. Concentrations of sucrose, sucralose, stevia, Neotame, neosucralose, and aspartame used to determine the sweetness equivalence of $7.0,5.2$, and $5.0 \%$ sucrose concentration in chocolate milk beverages using the magnitude scale, as defined by 11 assessors

\begin{tabular}{lcccccc}
\hline & \multicolumn{5}{c}{ Concentration $(\%, w t / w t)$} \\
\cline { 2 - 6 } Beverage & Sucrose & Sucralose & Aspartame & Stevia & Neosucralose & Neotame $^{1}$ \\
\hline Whole milk at $6{ }^{\circ} \mathrm{C}(7.0 \%)$ & 2.73 & 0.0052 & 0.018 & 0.0329 & 0.0088 & 0.0004 \\
& 4.37 & 0.0083 & 0.0289 & 0.0526 & 0.0140 & 0.0007 \\
& 7.00 & 0.0134 & 0.0463 & 0.0843 & 0.0225 & 0.0012 \\
& 11.2 & 0.0214 & 0.074 & 0.1349 & 0.036 & 0.0019 \\
Whole milk at $45^{\circ} \mathrm{C}(5.2 \%)$ & 17.92 & 0.0343 & 0.1185 & 0.2158 & 0.0576 & 0.0031 \\
& 32.03 & 0.037 & 0.0129 & 0.0235 & 0.0062 & 0.0002 \\
& 3.25 & 0.059 & 0.02 & 0.0376 & 0.01 & 0.0004 \\
& 5.20 & 0.095 & 0.033 & 0.0602 & 0.016 & 0.0007 \\
& 8.32 & 0.152 & 0.0528 & 0.0963 & 0.0256 & 0.0011 \\
& 13.312 & 0.2432 & 0.0845 & 0.1541 & 0.0409 & 0.0018 \\
& 1.95 & 0.0044 & 0.0154 & 0.0282 & 0.0075 & 0.0004 \\
& 3.12 & 0.0071 & 0.0247 & 0.0451 & 0.012 & 0.0006 \\
& 5.00 & 0.0114 & 0.0396 & 0.0722 & 0.0192 & 0.001 \\
& 8.00 & 0.0182 & 0.0623 & 0.1155 & 0.0307 & 0.0016 \\
& 12.8 & 0.0291 & 0.0996 & 0.1848 & 0.04915 & 0.0025 \\
\hline
\end{tabular}

${ }^{1}$ NutraSweet Corp., Chicago, IL.

suggested on commercial brand labels (20\% wt/wt) as the central point. One hundred consumers between the age of 18 and $60 \mathrm{yr}$ performed the test. All were consumers of powdered chocolate beverages, and most of the tasters were women (85\%). Tests for each set of samples were performed on different days.

\section{Selection of Judges}

To ensure reliable results, sensory discrimination testing was conducted before the analyses of magnitude estimation method. Preselection of the team of assessors was conducted with 25 candidates who were self-declared consumers of prepared powdered chocolate beverages and who demonstrated interest and availability to participate in the tests.

The discriminatory power of the candidates was evaluated according to Wald's sequential analysis (Meilgaard et al., 2006) using triangular tests and a significance level of $1 \%$ for sweetness with samples containing different concentrations of sucrose. The parameters used to define discriminatory power were $\mathrm{p}=0.45$ (maximum acceptable inability) and $\mathrm{p} 1=0.70$ (minimum acceptable ability), and the parameters for the risks were $\mathrm{a}=0.05$ (probability of accepting a candidate without sensory acuity) and $\mathrm{b}=0.05$ (probability of rejecting a candidate with sensory acuity; Moraes and Bolini, 2010).

\section{Determination of Sweetness Equivalence}

The determination of the amount of sweetener to be added and the sweetening power was conducted using the magnitude estimation method (Stone and Oliver,
1969), which provides direct quantitative measurements of subjective sweetness intensity. Eleven selected assessors were instructed on the method of magnitude estimation to ensure that the tests were accurately performed.

After preliminary instructions, assessors were taken to booths at the Laboratory of Sensory Science and Consumer Research of DEPAN/UNICAMP for the sampling procedure. Assessors analyzed samples sweetened with different sweeteners and sucrose at temperatures of $6 \pm 2^{\circ} \mathrm{C}$ and $45 \pm 2^{\circ} \mathrm{C}$ for whole milk and $6 \pm$ $2^{\circ} \mathrm{C}$ for skim milk. For skim milk, only the lower temperature was used for the magnitude estimation test, because no differences were observed between the hot and cold temperature conditions in the ideal sucrose concentration test.

Concentrations of sucrose and sweeteners used for the magnitude estimation test are shown in Table 1. The central concentration of each substance used for sweetness equivalence determination was based on available data from the literature and adapted for the product of the study in question (Cardoso et al., 2004; Palazzo et al., 2011). The other concentrations shown were obtained through multiplication by a factor of 1.6 (Stone and Oliver, 1969). Five concentrations were defined for each sweetener; the sweetener was added to the chocolate milk beverage prepared with hot or cold whole milk or cold skim milk, and then homogenized for $2 \mathrm{~h}$ before testing.

Samples were presented in individual booths using a balanced complete block design to minimize carryover effects among the samples (MacFie et al., 1989) and served in 50-mL clear disposable cups coded with random 3-digit numbers. In addition, a prepared chocolate 
milk beverage sweetened with sucrose was presented as a reference, which was defined using a JAR scale and coded with the letter $\mathrm{R}$. The judges were given the reference sample and told that it had an arbitrary value of 100. This was followed by several samples coded with random numbers and with sweetness intensities above and below the reference sample. The assessors were instructed to assign sweetness intensities for the coded samples relative to the reference sample and its assigned value. For example, a sample with half the sweetness of the sucrose reference would have a score of 50 , whereas a sample with twice the sweetness of the reference would have a score of 200. A score of 0 was not permitted.

Only samples with whole milk at 45 and $6^{\circ} \mathrm{C}$ and with skim milk at $6^{\circ} \mathrm{C}$ were analyzed. The results obtained were subsequently standardized by dividing the value found by each assessor by the respective geometric mean. Using standardized data, geometric means were calculated for each concentration of sucrose or sweetener. The logarithm of each concentration and each geometric mean was derived from standardized data for sucrose and other sweeteners. With obtained values, linear regression analysis was performed for log of sweetener concentration (x) and log of geometric means (y) for sucrose and different sweeteners for all samples at both hot and cold temperatures.

\section{Statistical Analysis}

The results of ideal chocolate powder concentration and sucrose concentration for chocolate milk beverages using JAR scale were obtained by using the FIZZ Network Sensory software (Biosystemes). The data were analyzed through simple linear regression and histograms, as suggested by Vickers (1998), using Excel 2007 (Microsoft Corp., Redmond, WA).
For the magnitude estimation method, the estimated sweetness values were converted to logarithmic values and expressed as the geometric mean. The concentration curves for the sensory response for each sweetener resulted in a power function with the following characteristics: $S=a \cdot C^{n}$, where $S$ is the perceived sensation, $C$ is the stimulus (sweetener) concentration, $a$ is the antilog of the y-intercept value, and $n$ is the slope of the straight line obtained (Moskowitz, 1974).

\section{RESULTS AND DISCUSSION}

\section{Ideal Powdered Chocolate Concentration}

After all data were collected, means were calculated for each chocolate powder concentration and added sucrose amount. A straight line and corresponding linear equation were obtained from which the ideal concentrations were calculated.

Based on the linear equation shown in Figure 1, the determined ideal chocolate powder concentration was $17.6 \mathrm{~g} / 160 \mathrm{~mL}$, which differs from the concentrations indicated by manufacturers on the product labels. This finding demonstrates the importance of first conducting sensory studies in different food matrices for each ingredient to be substituted or added to the product formulation. It is important to note that the correlation coefficient value $\left(\mathrm{R}^{2}=0.86\right)$ reflects the degree of consensus among consumers with respect to the analyzed attribute. The JAR scale has been used in several studies of different food matrices (Marcellini et al., 2005; Donadini et al., 2012) and appears to be highly applicable to the development and optimization of food product formulation.

The histogram in Figure 2 shows the score distribution for different chocolate powder concentrations based on the 9-point scale, where -4.5 corresponds to "much

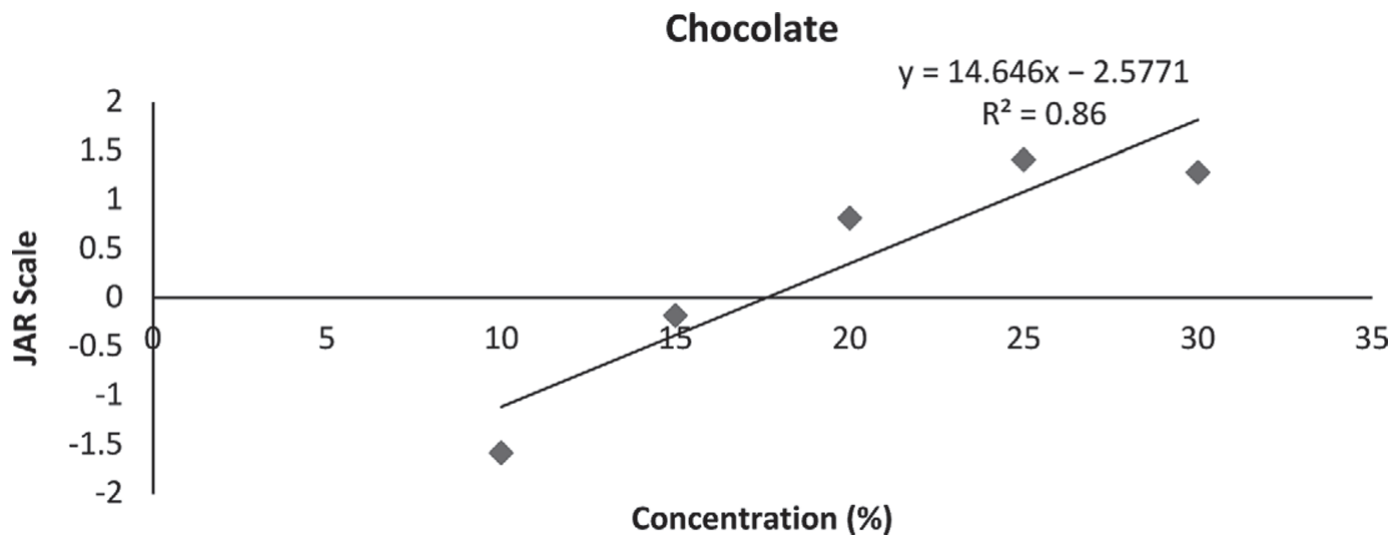

Figure 1. Ideal chocolate powder concentration of the chocolate milk beverage at $22^{\circ} \mathrm{C}$, determined using the just-about-right (JAR) scale by 100 beverage consumers. 


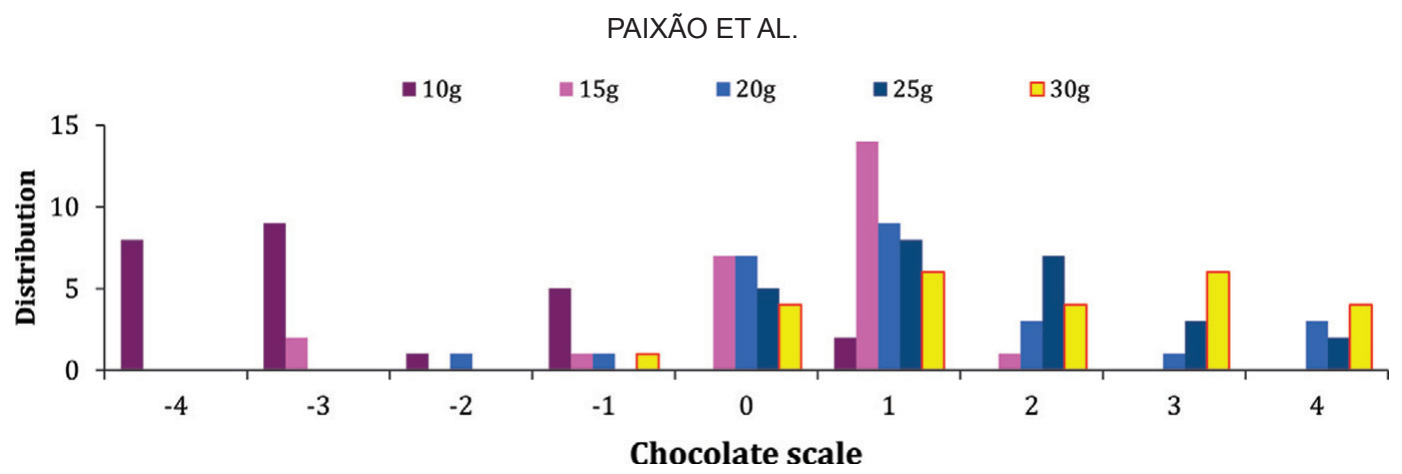

Figure 2. Histograms with the distribution of responses of 100 consumers in acceptance test for chocolate milk beverage samples with 10 , $15,20,25$, and $30 \mathrm{~g}$ of chocolate powder. Color version available in the online PDF.

less chocolate than the ideal," 4.5 corresponds to "much more chocolate than the ideal," and the central point (zero) corresponds to the ideal chocolate concentration. This distribution reinforces the results in Figure 1 and shows that the formulations containing 10 and $15 \mathrm{~g}$ of chocolate powder $/ 160 \mathrm{~mL}$ of water had the highest rate of responses at point zero. Thus, these concentrations were perceived as optimal by most consumers. In contrast, the formulations containing 20 and $25 \mathrm{~g}$ of chocolate powder $/ 160 \mathrm{~mL}$ of water had a high rate of responses for point 1 and 2 on the JAR scale, indicating that these sucrose concentrations were above the ideal for the consumers. We can therefore infer that the ideal chocolate powder concentration is between 10 and 25 $\mathrm{g} / 160 \mathrm{~mL}$.

\section{Ideal Sucrose Concentration}

Results of ideal sucrose concentrations are shown in Figure 3. The 3 samples presented high correlation coefficients; in whole milk samples, $\mathrm{r}=0.82$ at $6^{\circ} \mathrm{C}$ and $0.8545^{\circ} \mathrm{C}$, and for skim milk, $\mathrm{r}=0.93$ at $6^{\circ} \mathrm{C}$. For samples containing whole milk, the ideal sucrose concentrations were 7 and $5.2 \%$ (wt/wt) for the $6^{\circ} \mathrm{C}$ and $45^{\circ} \mathrm{C}$ beverage consumption temperatures, respectively. For skim milk samples, the ideal sucrose concentration was $5 \%$ at both temperatures.

Differences in ideal sucrose concentration at the 2 beverage consumption temperatures were only detected for whole milk: the ideal sucrose concentration was higher at $6^{\circ} \mathrm{C}$ than at $45^{\circ} \mathrm{C}$. Calviño (1986) previously showed that sucrose sweetness is greater when the beverage is

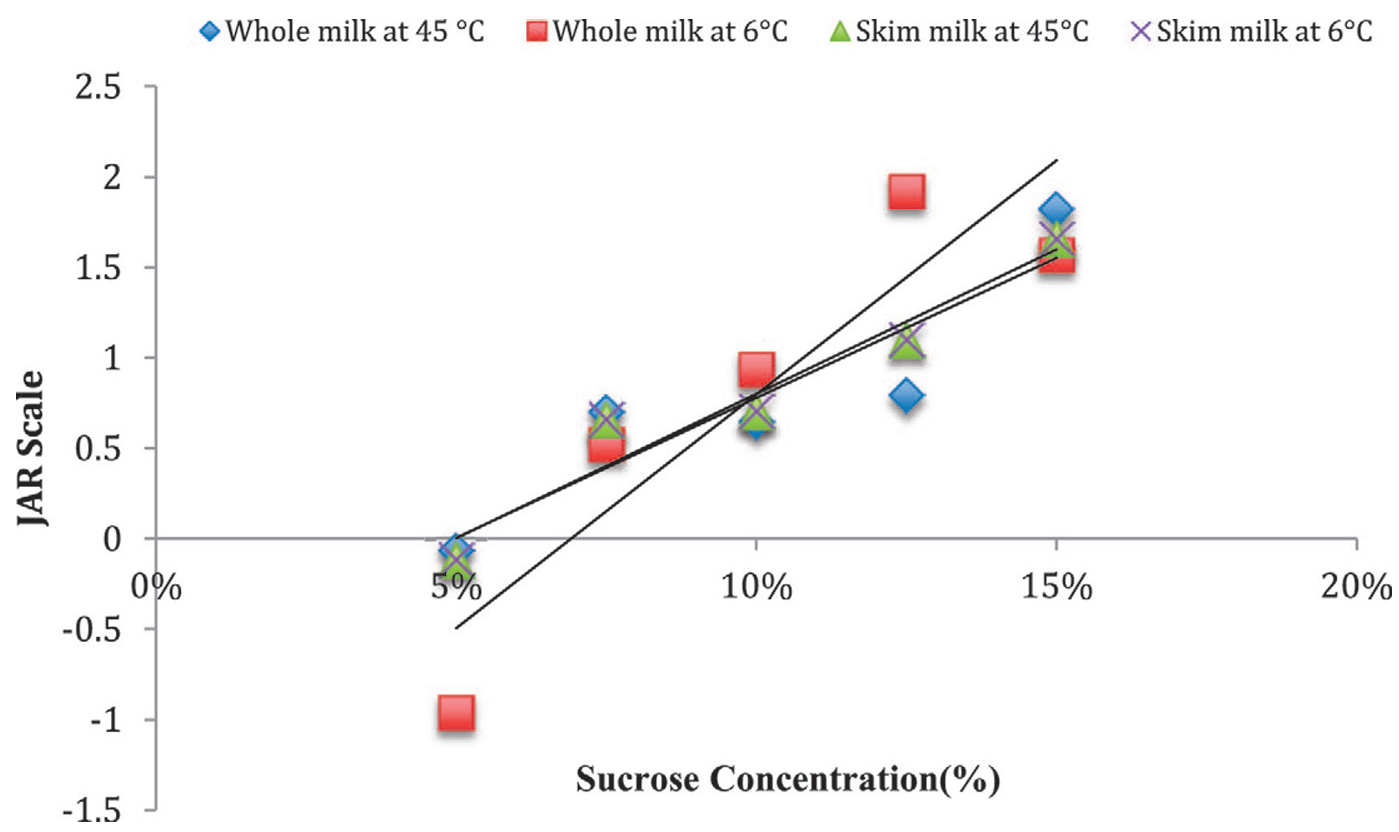

Figure 3. Ideal sucrose concentration to be added to chocolate whole milk beverage at $6^{\circ} \mathrm{C}$ and $45^{\circ} \mathrm{C}$ and to chocolate skim milk beverage at $6^{\circ} \mathrm{C}$ obtained with the use of a just-about-right (JAR) scale by 100 beverage consumers. Color version available in the online PDF. 


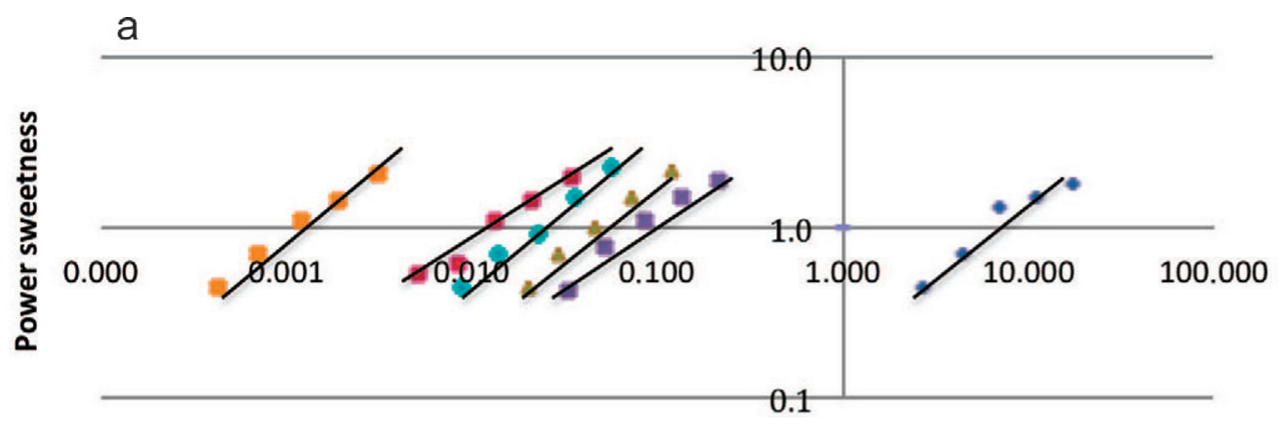

- Sucrose

- Sucralose

$\triangle$ Aspartame

- Stevia 95\% Reb

- Neosucralose

Neotame
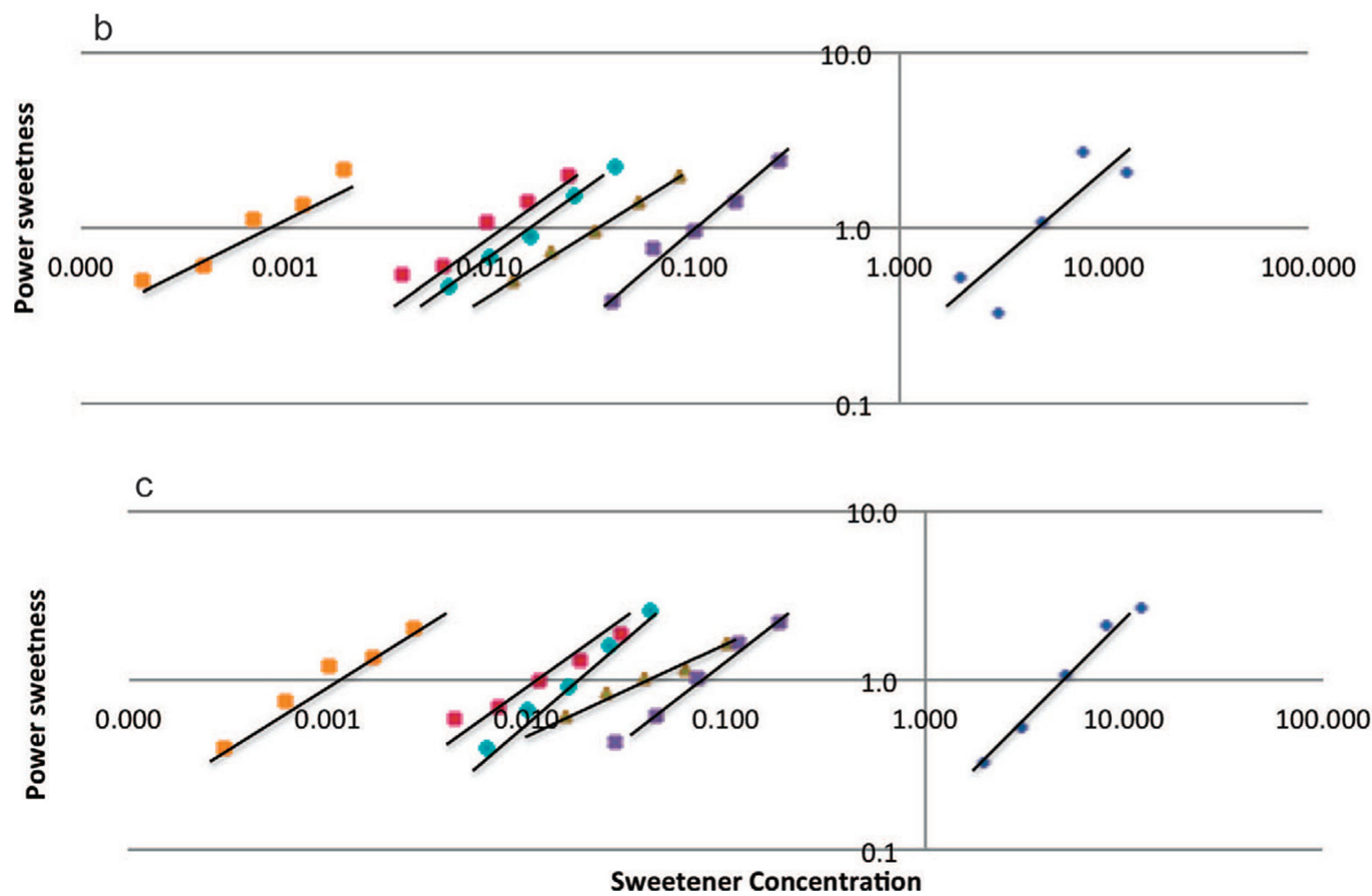

Figure 4. Relationships with the results of 11 assessors that performed magnitude estimation test among the sweetness intensities of the powdered chocolate beverages prepared with (a) whole milk at $6^{\circ} \mathrm{C}$, (b) whole milk at $45^{\circ} \mathrm{C}$, or (c) skim milk at $6^{\circ} \mathrm{C}$ and sweetened with stevia (with 95\% rebaudioside A), sucralose, aspartame, neosucralose, and Neotame (NutraSweet Corp., Chicago, IL). Color version available in the online PDF.

consumed at $37^{\circ} \mathrm{C}$ or $50^{\circ} \mathrm{C}$ than at $7^{\circ} \mathrm{C}$. Bartoshuk et al. (1982) similarly concluded that low sucrose concentrations were perceived with higher sweetness intensity as a function of increases in consumption temperature, thereby demonstrating the influence of temperature on perception of sweetness intensity. The present findings for whole milk are consistent with these previous reports.

The perception of sweet taste is linked to the interaction of "tasty" compounds with specialized receptors in taste buds of the tongue and palate and is transduced via electrical excitation of taste receptor cells. This excitation is transmitted to the brain, where the final representation of each taste modality is formed (Talavera et al., 2007). Data in the literature are conflicting concerning the dependence of sweet taste perception on temperature, which is due to both technical complications and large variability among individuals. The temperature dependence of mammalian gustatory nerve responses has been attributed to integrated electrical responses of afferent nerves (chorda tympani and glossopharyngeal nerves), which is consistent with main features observed in psychophysical assays in humans. It has been reported that temperature dependence of the magnitude of responses, including sweet taste perception, exhibits a bell shape with a peak at 20 to $30^{\circ} \mathrm{C}$ 
and that the thermal effects become weaker at higher stimulus concentrations (Talavera et al., 2007).

Shallenberger and Acree (1969), in their study with sucrose and sweeteners, hypothesized that sweetness increases as temperature increases, directly influencing sensory perception of the product. This theory was upheld by a recent study using water at low temperatures to assess the intensity of sweet taste in chocolate (Mony et al., 2012) and by another study using projective mapping on wines maintained at different temperatures (Ross et al., 2012). Increased perception of sweetness may also help mask undesirable sensory attributes such as the perception of bitterness in chocolate-flavored products, as reported in chocolate ice cream (Harwood et al., 2013). Nevertheless, this information cannot be generalized because of variation in the intensity of sweet taste perception when different studies are compared (Bartoshuk et al., 1982; Schiffman et al., 2000). This underscores the importance of studying the degree of sweetness in specific products because each product behaves differently. Thus, product-specific tests should be used more often to produce qualitatively better products that are sensorially appealing to consumers (Smith, 1971; McBurney et al., 1973; Moskowitz, 1973).

In this context, it would be a mistake to attribute the sweet taste of a given food to only a change in temperature. The phenomenon may also result from increased perception of sweetness by tasters and their ability to assess the sweet taste at different temperatures, which has recently been studied in wines (Ross and Weller, 2008). The changes in the perception of sweet taste may also be affected by the fat content of the milk or compounds derived from it (Francis et al., 2000).

In contrast to results obtained for whole milk, we found no differences in ideal sucrose concentration at 2 temperatures when skim milk was used, demonstrating the complexity of temperature dependence on sweet taste perception.

Histograms of score distribution for different sweetness concentrations were created from the results generated by consumers in the ideal test, with concentrations on a 9-point scale where -4.5 corresponds to "much less chocolate than the ideal," 4.5 corresponds to "much more chocolate than the ideal," and the central point (zero) corresponds to the ideal concentration of chocolate powder. The histogram demonstrated that increasing the temperature caused a decrease in the responses of tasters for points 1 and 2 of the JAR scale, indicating that a lower amount of sucrose should be added to the powdered chocolate milk beverage formulation when the beverage was consumed at a higher temperature.

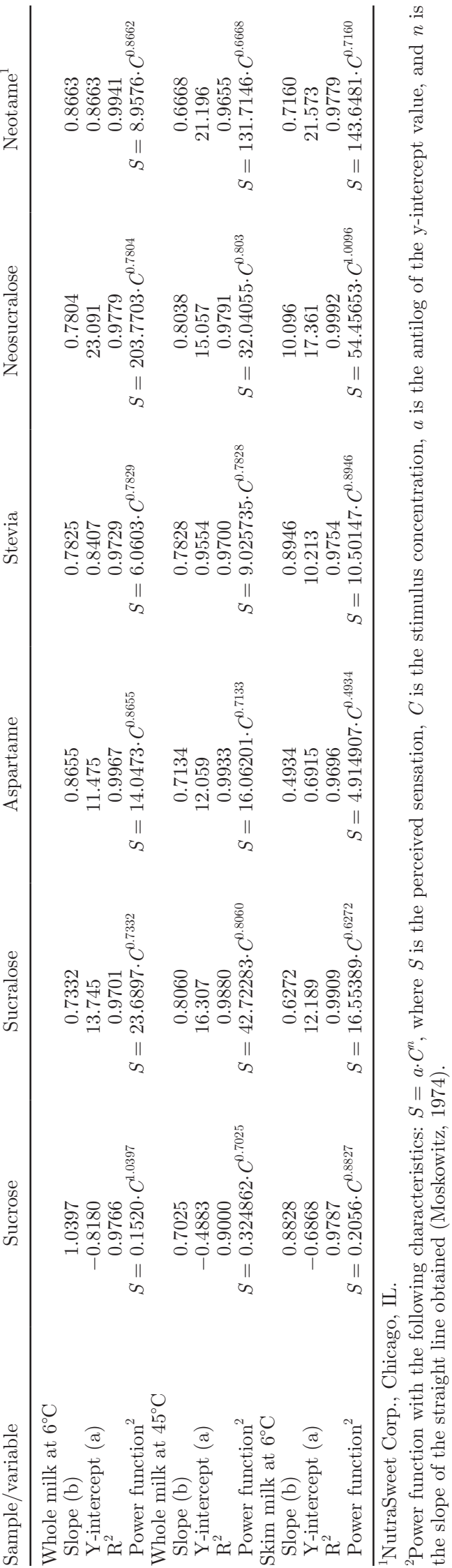


Table 3. Concentration equivalents $(\mathrm{CE} ; \%)$ and sweetening power equivalents (PE) of sucralose, stevia, aspartame, neosucralose, and Neotame ${ }^{1}$ in chocolate whole milk beverage at $6{ }^{\circ} \mathrm{C}(7 \%$ sucrose $)$ and $45^{\circ} \mathrm{C}(5.2 \%$ sucrose), and skim milk at $6^{\circ} \mathrm{C}(5.0 \%$ sucrose), determined using magnitude estimation method by 11 assessors

\begin{tabular}{lcccccr}
\hline Sweetener & $\begin{array}{c}\text { CE to 7\% } \\
\text { sucrose (\%) }\end{array}$ & $\begin{array}{c}\text { PE to 7\% } \\
\text { sucrose }\end{array}$ & $\begin{array}{r}\text { CE to 5.2\% } \\
\text { sucrose (\%) }\end{array}$ & $\begin{array}{r}\text { PE to 5.2\% } \\
\text { sucrose }\end{array}$ & $\begin{array}{r}\text { CE to 5.0\% } \\
\text { sucrose (\%) }\end{array}$ & $\begin{array}{r}\text { PE to 5.0\% } \\
\text { sucrose }\end{array}$ \\
\hline Sucralose & 0.0162 & 432 & 0.0170 & 294 & 0.0110 & 509 \\
Aspartame & 0.0550 & 127 & 0.0407 & 122 & 0.0390 & 143 \\
Stevia & 0.1 & 70 & 0.1130 & 44 & 0.0720 & 77 \\
Neosucralose & 0.0264 & 265 & 0.0247 & 202 & 0.0190 & 294 \\
Neotame & 0.0010 & 7,000 & 0.0013 & 3,846 & 0.0048 & 1,166 \\
\hline
\end{tabular}

${ }^{1}$ NutraSweet Corp., Chicago, IL.

\section{Magnitude Estimation Method}

The magnitude estimation test was not applied to skim milk samples at $45^{\circ} \mathrm{C}$; thus, we chose milk containing skim milk at $6^{\circ} \mathrm{C}$ for conducting the magnitude estimation method. For data analysis, geometric means of the values generated by each of the 11 judges were calculated for each of the considered samples. Results from this analysis are shown in Figure 4.

Slope values, y-intercepts, and linear correlation coefficients were determined for the collected data (Table 2 ). The straight line is the linear result of the simple power function $S=a \cdot C^{n}$, known as Stevens' power law or power function (Moskowitz, 1974). To determine equivalent concentration of each sweetener to sucrose, each variable of the power function was replaced. As shown in Table 3, different results between different samples at different temperatures were clearly observable. Increasing temperature resulted in a decrease in power for all of the sweeteners analyzed. The effect was particularly pronounced with Neotame and stevia, with the sweetening power reduced from 7,000 to 3,846 and from 70 to 44 , respectively. The decrease was less evident with aspartame and neosucralose, with the sweetening power reduced from 127 to 122 and from 265 to 202 , respectively. These results are interesting in terms of production as they may result in cost savings for the final product, coupled with a greater chance of marketing success as a result of the sensory optimization. Future studies should be conducted with consumers to confirm this hypothesis.

The present findings differ from those of Stone et al. (2012); however, sweetening agents used in their previous study were not high power (glucose and fructose) and no significant effects were detected with change in temperature. The present results also differ from those of Cardoso et al. (2004) for a soluble powder tea drink. In the present study, no major differences in sweetening power were detected for aspartame in any of the samples, and decreases in sweetening power were detected for stevia and sucralose as the temperature increased (Figure 5; Table 3).
The sweetening power of substances in relation to the consumption temperature of chocolate milk is shown in Figure 5. Neotame exhibited a decrease in sweetening power for both the $45^{\circ} \mathrm{C}$ whole milk beverage and $6^{\circ} \mathrm{C}$ skim milk beverage, with a more marked decrease in the latter. Although several authors have reported the sweetening power of Neotame to be 6,000 to 13,000 times greater than that of sucrose (Nofre and Tinti, 2000; Satyavathi et al., 2010; Palazzo et al., 2011), the sweetening power of Neotame observed in the present study was lower than expected. However, this finding is consistent with a previous suggestion by Moskowitz (1973) that the relative sweetness represented in Stevens' power equation (Stevens, 1957) by the intercept varies with temperature.

Studies of this nature highlight the importance of studying the sweetening power and sweetness equivalence of sweeteners in different food matrices. Besides avoiding a fixed amount of sweetener to be added to different products in a generalized manner, often reducing the cost of production, by using an appropriate amount of sweetener.

The present study demonstrates that the food matrix and product consumption temperature can dramatically influence the behavior of sweetening compounds in an unpredictable way. This information can be used by researchers and dairy processors when developing chocolate milk beverage formulations.

\section{CONCLUSIONS}

In chocolate milk beverage, the temperature at the time of consumption influenced the perception of sweet taste beyond differences in the amount of fat present in the product. In terms of increasing the probability of success in the consumer market, similar studies will be essential for the development of low-calorie products using sucrose substitutes and consumed at different temperatures. Additional studies should be carried out to determine the acceptability of the product, and the sensory descriptors that contribute to product acceptance should be identified. 


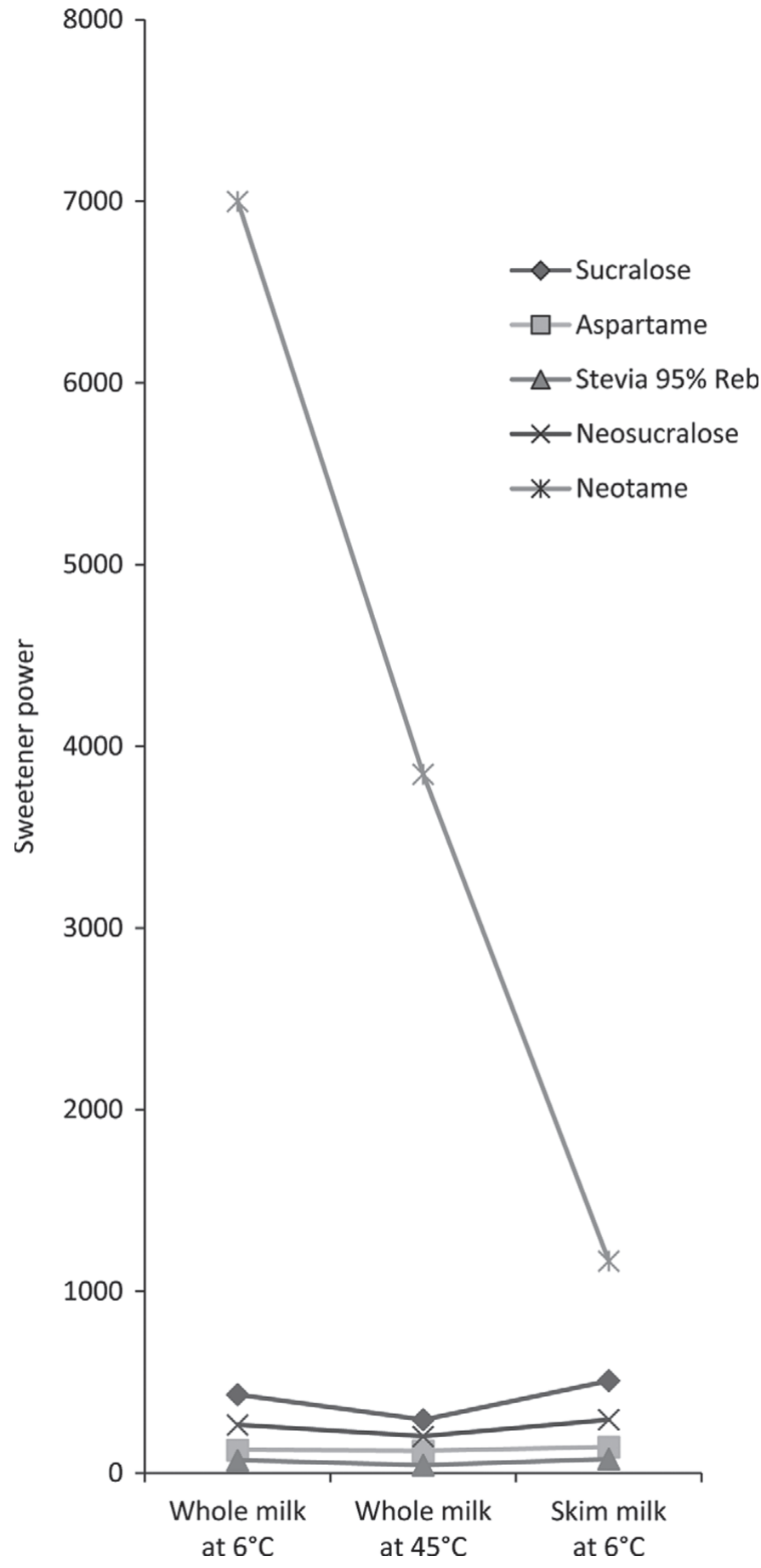

Figure 5. Representation of the sweetening power of different sweeteners in chocolate milk beverages as assessed by 11 assessors who performed the magnitude estimation test reported in Table 3.

\section{ACKNOWLEDGMENTS}

We thank CNPq (Brasília, DF, Brazil) for the scholarship granted and Embaré (Minas Gerais, Brazil) for raw materials donated, thus making this study possible.

\section{REFERENCES}

ABIAD (Associação Brasileira de Alimentos para Fins Especiais e Congêneres). 2011. Accessed Oct. 2, 2013. http://www.abiad.org.br/ index.php/noticias/83-abiad-lanca-cartilha-que esclarece-duvidassobre-adocantes.

ABMAPRO (Associação Brasileira de Marcas Próprias). 2011. Accessed Sep. 12, 2013. http://www.abmapro.org.br/page/noticias_ clipping_detalhes.asp?id=173.

Bartoshuk, L. M., K. Rennert, H. Rodin, and J. C. Stevens. 1982. Effects of temperature on the perceived sweetness of sucrose. Physiol. Behav. 28:905-910.

Brazil National Health Surveillance Agency. 2008. N.18 Resolution of 24 March 2008. Technical regulations authorizing the use of sweeteners in food additives with their respective ceilings. Official Diary, Brasilia, Brazil.

Cadena, R. S., and H. M. A. Bolini. 2012. Ideal and relative sweetness of high-intensity sweeteners in mango nectar. J. Food Sci. Technol. 47:991-996.

Calviño, A. M. 1986. Perception of sweetness: The effects of concentration and temperature. Physiol. Behav. 36:1021-1028.

Cardoso, J. M. P., J. R. Battochio, and H. M. A. Cardello. 2004. Equisweetness and sweetening power of different sweetening agents in different temperatures of consumption of tea drink in soluble power. Cienc. Tecnol. Alim. 47:448-452.

Desai, N. T., L. Shepard, and M. A. Drake. 2013. Sensory properties and drivers of liking for Greek yogurts. J. Dairy Sci. 96:74547466.

Donadini, D., M. D. Fumi, L. Valoni, and S. Porreta. 2012. Hedonic response to cheese in preschoolers. J. Sens. Stud. 27:176-187.

Esmerino, E. A., A. G. Cruz, E. P. R. Pereira, J. B. Rodrigues, J. A. F. Faria, and H. M. A. Bolini. 2013. The influence of sweeteners in probiotic Petit Suisse cheese in concentrations equivalent to that of sucrose. J. Dairy Sci. 96:5512-5521.

Francis, L. L., D. H. Chambers, S. H. Kong, G. A. Milliken, I. J. Jeon, and K. A. Schmidt. 2000. Serving temperature effects on milk flavor, milk aftertaste, and volatile compound quantification in nonfat and whole milk. Food Sci. 70:s413-s418.

Freitas, M. L. F., M. B. L. Dutra, and H. M. A. Bolini. 2014. Development of pitanga nectar with different sweeteners by sensory analysis: Ideal pulp dilution, ideal sweetness, and sweetness equivalence. Food Sci. Technol. (Campinas.) 34:174-180.

Harwood, M. L., J. R. Loquasto, R. F. Roberts, G. R. Ziegler, and J. E. Hayes. 2013. Explaining tolerance for bitterness in chocolate ice cream using solid chocolate preferences. J. Dairy Sci. 96:4938-4944.

MacFie, H. J., N. Bratchell, K. Greenhoff, and L. V. Vallus. 1989. Designs to balance the effect of order of presentation and first-order carry-over effects in hall tests. J. Sens. Stud. 4:129-148.

MarcelliniP. S.ChainhoT. F.BoliniH. M. A. 2005. Doçura ideal e análise de aceitação de suco de abacaxi concentrado reconstituído adoçado com diferentes edulcorantes e sacarose. Alim. Nutr. Araraquara 16:177-182.

McBurney, D. H., V. B. Collings, and L. M. Glanz. 1973. Temperature dependence of human taste responses. Physiol. Behav. 11:89-94.

Meilgaard, M. T., G. V. Civille, and B. T. Carr. 2006. Sensory Evaluation Techniques. CRC Press, Boca Raton, FL.

Mony, P., T. Tokar, P. Pang, A. Fiegel, J. F. Meullenet, and H. S. Seo 2012. Temperature of served water can modulate sensory perception and acceptance of food. Food Qual. Prefer. 28:449-455.

Moraes, P. C. B., and H. M. A. Bolini. 2010. Different sweeteners in beverages prepared with instant and roasted ground coffee: Ideal and equivalent sweetness. J. Sens. Stud. 25:215-225.

Morais, E.C., A. R. Morais, A. G. Cruz, and H. M. A. Bolini. 2014. Development of chocolate dairy dessert with addition of prebiotics and replacement of sucrose with different high-intensity sweeteners. J. Dairy Sci. 97:2600-2609.

Moskowitz, H. R. 1973. Effects of solution temperature on taste intensity in humans. Physiol. Behav. 10:289-292.

Moskowitz, H. R. 1974. Sensation and Measurement: Papers in Honor of S. S. Stevens. Reidel Press, Dordrecht, the Netherlands. 
Nabors, L. O. 2002. Sweet choices: Sugar replacements for foods and beverages. Food Technol. 56:28-35.

Nabors, L. O., and R. Lemieux. 1993. History of the commercial development of low-calorie foods. Pages 91-107 in Low Calorie Foods Handbook. A. M. Altschul, ed. Marcel Dekker Inc., New York, NY.

Nofre, C., and J. M. Tinti. 2000. Neotame: Discovery, properties, utility. Food Chem. 69:245-257.

Palazzo, A. B., M. A. R. Carvalho, P. Efraim, and H. M. A. Bolini. 2011. The Determination of isosweetness concentrations of sucralose, rebaudioside and neotame as sucrose substitutes in new diet chocolate formulations using the time-intensity analysis. J. Sens. Stud. 26:291-297.

Pimentel, T. C., A. G. Cruz, and S. H. Prudêncio. 2013. Influence of long-chain inulin and Lactobacillus paracasei subspecies paracasei on the sensory profile and acceptance of a traditional yogurt. J. Dairy Sci. 96:6233-6241.

Pinheiro, M. V. S., and A. L. B. Penna. 2004. Substitutos de gordura: Tipos e aplicações em produtos lácteos. Alim. Nutr. 15:175-186.

Ross, C. F., and K. M. Weller. 2008. Effect of serving temperature on the sensory attributes of red and white wines. J. Sens. Stud. 23:398-416.

Ross, C. F., K. M. Weller, and J. R. Alldredge. 2012. Impact of serving temperature on sensory properties of red wine as evaluated using projective mapping by a trained panel. J. Sens. Stud. 27:463-470.

Satyavathi, K., P. B. Raju, K. V. Bupesh, and T. N. R. Kiran. 2010 Neotame: High intensity low caloric sweetener. Asian J. Chem. 22:5792-5796.
Schiffman, S. S., E. A. S. Miller, B. G. Graham, J. L. Bennet, B. J. Booth, N. Desai, and I. Bisahy. 2000. Effect of temperature, pH, and ions on sweet taste. Physiol. Behav. 68:469-481.

Shallenberger, R. S., and T. E. Acree. 1969. Molecular structure and sweet taste. J. Agric. Food Chem. 17:701-703.

Shepard, L., R. E. Miracle, P. Leksrisompong, and M. A. Drake. 2013 Relating sensory and chemical properties of sour cream to consumer acceptance. J. Dairy Sci. 96:5435-5454.

Smith, D. V. 1971. Taste intensity as a function of area and concentration: Differentiation between compounds. J. Exp. Psychol. 87:163-171.

Stevens, S. S. 1957. On the psychophysical law. Psychol. Rev. 64:153181

Stone, H., R. N. Bleibaum, and H. A. Thomas. 2012. Sensory Evaluation Practices. 4th ed. Academic Press, New York, NY.

Stone, H., and S. M. Oliver. 1969. Measurement of the relative sweetness of selected sweeteners and sweetener mixtures. J. Food Sci. $34: 215-222$.

Talavera, K., Y. Ninomiya, C. Winkel, T. Voets, and B. Nilius. 2007. Influence of temperature on taste perception. Cell. Mol. Life Sci. 64:377-381.

Varnam, A.H.; Sutherland, J. P. 1997. Bebidas: Tecnología, Química y Microbiología. Vol. 2. Acribia S.A., Zaragoza, Spain.

Vickers, Z. 1998. Sensory specific satiety in lemonade using a just right scale for sweetness. J. Sens. Stud. 3:1-8. 